\title{
A Survey of Toulmin Argumentation Approach for Medical Applications
}

\author{
https://doi.org/10.3991/ijoe.v18i02.28025
}

\author{
Hamzah Noori Fejer $\left.{ }^{1}{ }^{\square}\right)$, Ali Hadi Hasan ${ }^{1}$, Ahmed T. Sadiq ${ }^{2}$ \\ ${ }^{1}$ College of Information Technology, University of Babylon, Babylon, Iraq \\ ${ }^{2}$ Department of Computer Science, University of Technology, Baghdad, Iraq \\ hamzah.fejerestudent. uobabylon.edu.iq
}

\begin{abstract}
The argumentation field in Artificial Intelligence has increases significantly resulting in a practical body of work. This survey explores the techniques that are used to accomplish the foundations for argumentation. It also provides a review of the recent advances in the argumentation techniques that specialize in using Toulmin's model when dealing with conflicting problems in the medicine domain. It also displays a discussion of the challenges faced in the automatic extraction of a deeper understanding of inference techniques. The drug conflict problem is considered to be one of most challenging aspects in medicine filed in the world. This survey also reviews Toulmin's model of argumentation in terms of solving conflicting problems in different domains that are specialized in solving drug conflicts in medicine.
\end{abstract}

Keywords - argumentation, artificial intelligence, Toulmin's model, drugs conflicting problem

\section{$1 \quad$ Introduction}

Argumentation is a relatively new topic of artificial intelligence that has a wide range of applications in fields as diverse as management, law, political science, medicine, mathematics, and others. The goal of using argumentation is to increase the computer's ability to prove and debate opinions, sentiments, and theorems. Argumentation is a term that is used almost every day, yet it is used in a number of circumstances. Probably the most well-known way of thinking about arguments in everyday life is that they are activities that individuals engage in when they are in conflict and disagree with one another.

The importance of persuasive speech has given rise to a long history of argumentation. Rhetoric and argumentation theory arose from the study of the structure of arguments by a number of researchers [1]. Others applied similar models to issues involving knowledge representation, legal reasoning, and negotiation.

The task of demonstrating or disproving a statement is known as argumentation. It is suggested that it is used for inducing new concepts, establishing truths, or opposing errors in another person's mind. This definition of argumentation also uses the term argument for referring to a specific issue that is the result of reasoning [2]. Many 
argumentation models were proposed by researchers for various things. The practice of finding argumentative components in natural language texts is known as argument mining [3]. Identifying argument components can help readers organize their thoughts and benefit argumentation authors in developing a persuasive argument. Primary components of argumentation that are determined in Toulmin's argumentation model (1958) are used as methods for constructing arguments, such as a claim, data, and a warrant, have been frequently used to aid argumentation for problems resolution in various fields, including scientific education [4].

Stephen Toulmin lays forth a practical approach to the interpretation of arguments. His structural model entails recognizing and isolating the various components of argumentation into a discernible order and structure so that argumentation may be scrutinized thoroughly. The components of this model and how they relate to one another might help clarify how this model of study evidence is used in medicine. This paper can be outlines according to the following structure: the second section explains the use of argumentation to make a decision support. Toulmin's model is explained in the third section. Finally, the conclusion is represented in the last section.

\section{Argumentation theory}

Argumentation theory, or argumentation, is an interdisciplinary study of how logical reasoning can lead to conclusions; that is, statements based on the premises, whether voted on or not. It includes civic discussion, discourse, and persuasion as arts and sciences. It looks at inference, logic, and procedural rules in both natural and artificial environments. Argumentation entails deliberation and bargaining, both of which are fundamental to the rule of collaborative decision-making. An argumentation framework is a mechanism for dealing with contested material and drawing conclusions from it using formalized arguments in AI and related domains. The inputlevel information in an abstract argumentation method is a collection of abstract arguments. It can be represented through the application of binary connections to a group of arguments, whereby conflicts between arguments can be avoided. The attack relation can be represented by arrows, and the framework of an argument can be represented by a graph as arguments as a node. Many adaptations of Dung's framework have been discovered, such as logic-based argumentation methods and value-based argumentation methods.

The argumentation is a sub-discipline of philosophical logic that has grown beyond its basic context to become a major topic of logic-based artificial intelligence in the recent decade [5]. Given the development of formal models, which are represented by human-like reasoning, the argumentation theory gained importance over time.

Abstract argumentation methods are shown to be useful in modeling and examining defensible reasoning processes $[1,2,3,5]$. Argumentation begins with the use of a knowledge base and the formalization of arguments. The second level necessitates the explanation of numerous defeat relationships. Argument and defeat relationships are grouped in an argumentation framework for evaluation. The use of acceptability se- 
mantics for computing arguments is a step after determining the justification status and their rational acceptation [6].

The argumentation theory states that given a set of arguments, some of which are antagonistic to others, a decision must be made as to which arguments can be accepted. It is not enough to look at an argument's defeaters to evaluate its acceptance status; it also necessary to establish whether the defeaters are opposed to one another.

\subsection{Basics}

Arguments can be defined as a non-empty set of premises that support several conclusions. Conclusions and premises are text parts that express propositions. The argument can be represented visually as an argument diagram, with nodes of propositions serving as support and an arrow connecting the conclusion and premise nodes [2].

In its most basic form, the argument consists of two propositions: the first is the conclusion, which is supported by only one premise as shows the structure in Figure 1a. The conclusion of an argument is supported by many premises that can only be expressed as a connected structure if they are taken collectively, according to Freeman's terminology [3]. None of the related premises could sustain the conclusion on their own as depicted in the diagram. The linked support is shown in Figure 1b through the connection of premises before their linking to the conclusion.

Argumentation is a structure that occurs when a number of arguments are linked to one another and form a nation of greater complexity. The manner in which arguments related to larger complexes are attacked or supported can be described as attacking or supporting. Each of them can be described as follows:

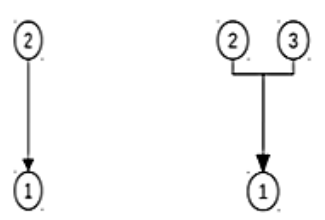

(a)basic argument (b)linked support

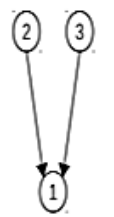

(c)multiple support
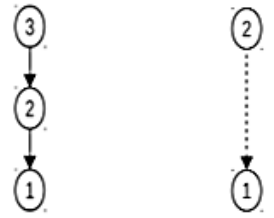

(d)serial support (c)example support

Fig. 1. Basic support relation and complex formation

Argumentation Supporting. There are a variety of approaches that can be employed to support the argumentation's conclusion. The first method is to gather as many arguments as possible for the same conclusion; the second method is to expand on the argument already obtained. The method of the author presenting a different, but similar conclusion might be applied to a fresh argument. All of the arguments stand on their own, and the author could make one of them without the other. To avoid confusion with Freeman's convergent structure, this structure can be called multiple supports [3].

As shown in Figure 2c, the new argument is linked forward to the same conclusion is represented by a graph with different arrows to connect the new argument to the 
common conclusion, utilizing the premises. Another option to provide more support for the conclusion is to continue building the argument by supporting either argument's premise. A new argument can be presented by one author in order to persuade another of the validity of a premise [4]. It indirectly supports the conclusion by explicitly supporting the premise.

The supported text segment has two functions: one serves as a premise in the original argument, and the other serves as the conclusion of the subsequent argument [5]. Following the terminology of Freeman, the structure that results might be referred to as serial. As demonstrated in Figure 2d, such a serial structure can be simply displayed in the diagram argument by connecting the premises of the new argument to their conclusion, being one of the premises of the original argument.

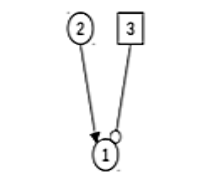

(a)basic argument

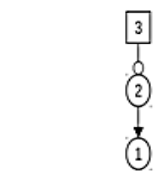

(b)rebut a prim

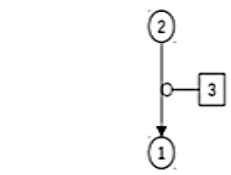

(c)undercut an argument

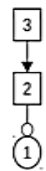

(d)supporting a rebut

Fig. 2. Types of support

Argumentation in decision making. For a long time, decision making, which is commonly considered as a sort of reasoning toward action, has piqued the curiosity of various scientists, including computer scientists. Every decision problem entails choosing the best possible actions from a set of options, based on a wealth of knowledge about the current condition of the world and the probable actions as a result. There may be insufficient or ambiguous information available [7]. Economists have mostly created classical decision theory, which focuses on determining what constitutes a rational decision maker. They've prepared a list of guidelines for comparing a variety of options.

In the present state, partial information is mixed with complete information about the given state of the world, creating a collection of the possible actions as inputs. Next, a function evaluates the value of consequences of the actions obtained. In other words, the methodology creates a distinction between preferences and knowledge. Both are encoded by means of a distribution function evaluating the plausibility of various world states, and it uses a function to encode preferences through the prediction of the extent to which the result is desirable. Due to its explanatory strength, argumentation is the most appropriate tool of defense. Many scholars have only recently introduced argumentation in the decision making analysis [6]. Practically, decisions are made according to the arguments and counter-arguments in everyday life. Argumentation could be of use to explain the decisions that have already been made. A decision-making model returns an ordering on a number of options, which might be partial or wholly based on the decision criteria encoded. In this study, Toulmin's argumentation model will be used to compute argumentation support and argumentation against for drugs. Next, decision are $\mathrm{ti}=\mathrm{o}$ be made regarding whether or not this drug should be taken based on higher value which is computed by means of a qualifying function. 


\section{Toulmin's model argumentation}

The most in-depth examination of argument structure and representation presented in this work is based on Stephen Toulmin's approach in the uses of argument (1958). Toulmin's goal was to figure out why formal logics in philosophy provided such a brief overview of human reason, and to devise a new structure of a logical nation based on practical reasoning analysis. Toulmin offered a method for evaluating the logical microstructure of ordinary arguments, based on analysis in philosophy of the syllogism [8], and based on the notion that argumentation is "a major site of practical human thinking". Toulmin's purpose is to construct a variety of 'practical arguments,' also known as significant arguments, which are typically lacking in practical significance. Toulmin's practical argument, on the other hand, aims to align on the justifying function of the argument versus the deductive function of theoretical arguments [9]. The practical arguments in the first obtain a claim of interest, and then give explanation for it, meanwhile theoretical arguments made inferences according to a number of principles so as to arrive at a claim.

Toulmin believes that reasoning is less active than inference including the exploration of new ideas, but more active including the testing and filtering of already established concepts. This is a goal that can be achieved via the task of justification. Toulmin believed that a good justification for a claim was essential for a strong argument to succeed [7].

Toulmin proposed a structure for assessing arguments in uses of argument (1958), which includes six connected components:

Claim (Conclusion): A conclusion must be reached, whereas Ground (Evidence, Data, Fact) is information that can be used as the claim's foundation. The Warrant is a declaration of intent to proceed from the ground to the claim. When the warrant is insufficient for the readers or listeners, more support must be provided. Rebuttal statements are remarks that can be used to refute a claim. Qualifiers are words or phrases that convey the speaker's level of assurance or force in making a claim. Words or phrases that come to mind are (probably, possible, impossible, certainly, presumably and necessarily). The claim and the warrant are believed to be the most important in practical arguments, but backing, qualifier, and rebuttal may not be necessary in other cases. Figure 3 shows the interrelationships of Toulmin's components of argument.

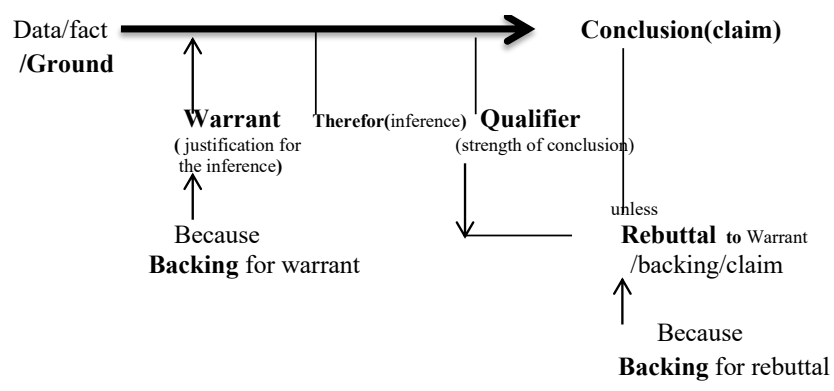

Fig. 3. Relationship between the Toulmin's model components 


\subsection{Toulmin's model in conflicting problem}

Stephan Toulmin devised an argumentation approach that demands the application of logical structure, not for proving a point, but in order to persuade others of the validity of the points within arguments. In writing an essay, the writer aims to persuade the reader to accept or reject the argument by means of claims, because clauses, grounds, warrants, backing, rebuttal, and qualifiers [10] are used in Toulmin's model for justifying the argument via the primes are available or prove opposing the argument. These tend to be competing between support primes and attack primes. The winner will be determined by the strength of the evidence, which means that Toulmin's model will be utilized to solve the disagreement because it has a logical structure for this purpose.

Toulmin's model is utilized in a variety of fields to settle conflict situations. In the field of education, it is employed in the production of academic essays. Toulmin's model outlines the essential processes in writing an essay (primes, conclusion). Many unclear issues and contradicting problems will be accrued if Toulmin is used as an interpreter in law. Toulmin has been used in medicine in a variety of ways, including clinical guidelines, health care, and resolving conflicting clinical guidelines for patients based on their condition and preferences. The next sections show previous works that make use of Toulmin's model for solving conflicts and problems.

Kristijonas et al. [11] proposed a novel structured argumentation formalism for reasoning with competing clinical guidelines, preferences, and patient-specific data. They integrated goal-driven and assumption-based logic options among the results of thinking, especially assuming the applicability of the guiding recommendations related to the overall goal of the patient's well-being. They resolve conflicts between recommendations using the patient's conditions and preferences, after which the priority of patient-focused goals is considered to accomplish non-conflict results. They recommend the maximizing of goals with respect to the preferences.

Paul Reisert et al. [12] focused on use Toulmin's models and its treatment form for policy discussions. It may be applied to daily arguments inversed to a certain field. They create a computer model for automatically constructing a Toulmin's argumentation form from the web using keywords. The most challenging part of automating Toulmin's instantiation is determined by the semantic relationship between sentences.

Cynthia R Collins in [13] assumed that a substantive argument or claim can be evaluated according to the assumptions it makes warrant and the strength of the evidence base backing. They used Toulmin's model for creating analysis solutions to hard issues. This model usually provides researchers with a first, real learning experience in specifying the domain and the challenges of framing clinical cases.

Vagner Gabriel et al. [14] presented an argumentation based on the inference form for BDI agents, with the goal of providing components that support agent belief reasoning. Toulmin's model of argumentation was utilized for developing argumentation and presenting the evolution of argumentation based on inference structure to BDI agents. The agent can use this architecture to form new beliefs based on new facts and prove those beliefs. Arguments determine the weight in this manner, thereby making it easy to be checked. This approach also allows for the use of many qualified func- 
tions for implementation, so it can be applied to a variety of domains. The advantage of employing the created methodology is that it allows for a modular investigation of an argument, thereby allowing each component of the framework to be examined individually.

Hong \& Abdul Talib in [15] suggested the use of Toulmin's model for promoting scientific argumentation in a chemistry learning. Based on the application of Toulmin's model in science education and the nature of chemistry, the use of Toulmin's model undergoes a further elaboration so as to overcome its limitations.

Admoko et al. [16] used Toulmin's argument pattern and provided an alternative recognition of the "infodemic" in the Covid-19 Pandemic era for determining the validity of information [17]. This argumentation pattern identifies three core components as well as three additional components from a connected argumentative filed. Table 1 shows the preview works that used Toulmin's model argumentation when dealing with conflicting problems.

Table 1. It show the preview works that used Toulmin's model argumentation in conflicting problems

\begin{tabular}{|l|l|l|l|}
\hline Reference \& year & \multicolumn{1}{|c|}{ Approach } & \multicolumn{1}{c|}{ Advantages } & \multicolumn{1}{c|}{ Limitations } \\
\hline $\begin{array}{l}\text { Paul Reisert } \\
\text { Et al 2015 }\end{array}$ & $\begin{array}{l}\text { They used Toulmin's model as a } \\
\text { treatment form for policy debates. } \\
\text { They build a computational model } \\
\text { for automatic building. }\end{array}$ & $\begin{array}{l}\text { It can be applied to daily } \\
\text { arguments inversed to a } \\
\text { certain field. }\end{array}$ & $\begin{array}{l}\text { Semantic relations } \\
\text { between sentences } \\
\text { of argumentation }\end{array}$ \\
\hline $\begin{array}{l}\text { Cynthia R Collins } \\
\text { 2016 }\end{array}$ & $\begin{array}{l}\text { They used Toulmin's Model of } \\
\text { Logical Argument as a guide to } \\
\text { define a beginning insightful re- } \\
\text { search problem statement. Toul- } \\
\text { min's model is used } \\
\text { to analyze and create solutions for } \\
\text { complex or emergency problems }\end{array}$ & $\begin{array}{l}\text { It allows logic tools to be } \\
\text { applied to a variety of } \\
\text { problems interdisciplinary } \\
\text { knowledge building in } \\
\text { nursing and health scienc- } \\
\text { es. }\end{array}$ & $\begin{array}{l}\text { Identify the scope } \\
\text { of the argument and } \\
\text { limit the impact of } \\
\text { anticipated rebuttals }\end{array}$ \\
\hline $\begin{array}{l}\text { Vagner Gabriel } \\
\text { Et al 2018 }\end{array}$ & $\begin{array}{l}\text { They describe the development of } \\
\text { argumentation depending on infer- } \\
\text { ence structure to BDI agents, using } \\
\text { Toulmin's model for argument } \\
\text { development. }\end{array}$ & $\begin{array}{l}\text { It allows for a modular } \\
\text { investigation of an argu- } \\
\text { ment, examining each } \\
\text { component of the frame- } \\
\text { work individually. }\end{array}$ & $\begin{array}{l}\text { It needs to compute } \\
\text { weights of all } \\
\text { beliefs. }\end{array}$ \\
\hline $\begin{array}{l}\text { Hong \& Abdul } \\
\text { Talib, 2018 }\end{array}$ & $\begin{array}{l}\text { They used Toulmin's model in the } \\
\text { analysis and identification of rhetor- } \\
\text { ical and linguistic structures realized } \\
\text { in the students' essays. }\end{array}$ & $\begin{array}{l}\text { They developed Toulmin's } \\
\text { model argumentation. }\end{array}$ & $\begin{array}{l}\text { It cannot be used in } \\
\text { the rebuttal stage. }\end{array}$ \\
\hline $\begin{array}{l}\text { They identified the "infodemic" in } \\
\text { the Covid-19 Pandemic era through } \\
\text { the assessment of invalid infor- } \\
\text { mation by using the Toulmin's } \\
\text { argument Pattern. }\end{array}$ & $\begin{array}{l}\text { They provided an alterna- } \\
\text { tive approach for recogniz- } \\
\text { ing and determining the } \\
\text { validity of information. }\end{array}$ & $\begin{array}{l}\text { It needs three } \\
\text { additional compo- } \\
\text { nected from a con- } \\
\text { tive field. }\end{array}$ \\
\hline
\end{tabular}

\subsection{Toulmin's model in medicine}

There are many works that use both argument construction and argumentation semantics for reasoning with medical knowledge, as well as many tools in support of argumentation theory and several proposals. Many works use both argument construc- 
tion and Toulmin's argumentation for reasoning with medical knowledge to focus on argumentation frameworks.

Green in [18] built a freely accessible collection of full-text and open scientific publications from the biomedical genetics research literature that are described in support of research. As a result, building such systems presents problems, such as the widespread usage of biological, chemical, and clinical words in the field of BioNLP. These difficulties are shed light upon by Green in [19], who provides initial guidance for manually identifying ten bespoke argument schemes for genetics research articles.

Stab and Gurevych et al. [20] used their already annotated corpus. They study categorized sentences into numerous classifications including none, claim, and premise. They earned a 0.72 macro-F1 score. By displaying 90 contentious articles, they outlined the primary claims and allegations, the installations, and their support and attack linkages. They got 0.72 for argument components and 0.81 for component relationships.

Francisco and Elizabeth in [21] tried to provide items for analyzing and comparing selected methods and contribute to an argumentative ability that enhances participants' chances of interaction. Their study illustrates the interaction between the health care team, patients, and doctors. Using argument theory as unique applicationin medicine field, and Toulmin's model argumentation is used for analyzing the validity of clinical arguments.

Jacky VISSER et al. [22] provided arguments using two classification approaches in this study: Walton's common categorization [23] and Wagemans' newly designed periodic table of arguments. They presents annotation requirements for every categorization approach before applying them to a corpus of arguments from the 2016 US presidential debates. They accomplishes particle inter-annotator agreement and obtain what they believe are the most two consistently annotated corpora of argument procedure of conversational argumentation currently accessible, to the best of their knowledge.

Green in [24] used generate argument method (Prolog rules), which might be improved. They match the Prolog knowledge base collected with the body of each rule from the text in the proposed study, which necessitate some discourse knowledge in order to construct what Prolog facts.

Wilk et al. [25] proposed a method for clinical guidelines execution. They dealt with the preferences of patients as well as their individual medical situations. The graph is used to provide recommendations. They introduced preferences and patient conditions, which are then mapped into First Order Logic (FOL) rules using FOL operators.

Green in [26] provided an argument action method and inter-argument relations for the annotation of arguments in study papers. In one of a few researches that presented in an argument concert on the biomedical filed. As a result, annotation schemes can be used to extract arguments from RCT abstracts in part. To put it another way, they work together to resolve conflicts among guideline recommendations, and specify therapy superiority based on clinical trials when managing among morbidities.

Gupta et al. [27] extracted comparative forms from biological texts. They used syntactic form and dependency parsers. Those who created syntax-based tree kernels to 
justify their choice, so that the amount of contentious content in their dataset is compared. RCTs are a frequent approach of aggregating evidence in support of medical decisions. As a result, arguments are represented in the $[0,1]$ range, where 1 indicates arguments which can be easily interpreted.

Green in [28] investigated how argumentation systems implemented as logic programs in Prolog utilized for extracting individual arguments. The approaches are now expressing in terms of semantic predicates extracted from a text utilizing BioNLP tools.

MAYER et al. [29] found evidence and made claims from RCTs (Randomized Clinical Trials). They developed a new annotated data set that is centered on four diseases: glaucoma, diabetes, hepatitis B, and hypertension, with 976 argument components, 697 pieces of evidence, and 279 claims. The predictability of particle outcomes explains the method's applicability to a variety of medical fields. They proposed extracting argumentative information from clinical data using an automated methodology. Their study may be the first to use argument tools to automatically extract claims and evidence from clinical trials.

Kokciyan et al. [30] employed computational argumentation, a logic-based methodology that provides a formal means for reasoning with evidence by substantiating claims for and against particular conclusions. They proposed the architecture of CONSULT system to illustrate how facts are gathered about the patients and their different preferences. A logic-based representation of official treatment guidelines by different public health agencies is provided. Logical arguments are constructed from these facts and guidelines; these arguments are analyzed to solve inconsistencies concerning various treatment options and patient/clinician preferences [31].

Tobias Mayer et al. [32] introduced Argumentative Clinical Trial Analysis (ACTA), a tool developed to assist doctors with clinical trial analysis. ACTA analyzes the user-supplied textual abstract assessments of clinical trials and recognizes the argumentation components of their relationships. They study introduces a method for mechanically assessing clinical trial abstracts from an argumentation standpoint.

Eli Moser and Robert E. Mercer in [33] tested five biochemistry journal publications and produced a report on the large-scale argumentation type they discovered. One finding from our analysis of biochemistry articles is that the reasoning strategy developed for genetic study articles can be applied to experimental biomedical literature in the public domain [34]. They used argumentation methods to explain the claims based on experimental data and other claims. These models involve the manual examination of the biochemistry articles obtained.

Tobias Mayer et al. [35] proposed a complete argument architecture for identifying argument components as evidence and claims, and predicted the relationship as attack or support between argument components. They also discovered a dataset by annotating 500 RCT abstracts from the MEDLINE database, which including neoplasm, glaucoma, hepatitis, diabetes, hypertension. They obtained a macro F1-measure of $(0.68)$ for relation prediction and ( 0.87$)$ for component detection. Table 2 summarizes these works. 
Paper-A Survey of Toulmin Argumentation Approach for Medical Applications

Table 2. Previous works in the medicine domain

\begin{tabular}{|c|c|c|c|}
\hline $\begin{array}{l}\text { Reference } \\
\text { \&year }\end{array}$ & Approach & Advantages & Limitations \\
\hline Green 2014 & $\begin{array}{l}\text { They aim to create a freely } \\
\text { available collection of open texts } \\
\text { of scholarly articles from the } \\
\text { research literature in biomedical } \\
\text { genetics. }\end{array}$ & $\begin{array}{l}\text { To build open scientific } \\
\text { publications from the biomed- } \\
\text { ical genetics described in } \\
\text { support of .research }\end{array}$ & $\begin{array}{l}\text { Wide spread usage of } \\
\text {,biological, chemical and } \\
\text { clinical words . }\end{array}$ \\
\hline $\begin{array}{l}\text { Stab } \\
\& \text { Gurevych } \\
2014 \text { a }\end{array}$ & $\begin{array}{l}\text { They explain the major claims } \\
\text { and their relationships (support- } \\
\text { ing and attacking). }\end{array}$ & $\begin{array}{l}\text { They got high accuracy } \\
\text { results by used F-measure. }\end{array}$ & $\begin{array}{l}\text { Difficult to find relations } \\
\text { between argument compo- } \\
\text { nents. }\end{array}$ \\
\hline $\begin{array}{l}\text { Stab \& } \\
\text { Gurevych } \\
2014 b\end{array}$ & $\begin{array}{l}\text { In this study, sentences are } \\
\text { classified into many classes, such } \\
\text { as none, major claim, claim, and } \\
\text { premise, using their previously } \\
\text { annotated corpus. }\end{array}$ & $\begin{array}{l}\text { They got high accuracy } \\
\text { results by using F-measure. }\end{array}$ & \\
\hline $\begin{array}{l}\text { Francisco } \\
\text { and Eliza- } \\
\text { beth } 2015\end{array}$ & $\begin{array}{l}\text { They illustrate the interaction } \\
\text { between the health care team, } \\
\text { patients and doctors. }\end{array}$ & $\begin{array}{l}\text { They found a unique applica- } \\
\text { tion using Toulmin's model } \\
\text { in the medicine field. }\end{array}$ & \\
\hline $\begin{array}{l}\text { Jacky } \\
\text { VISSER } \\
\text { et al. } 2016\end{array}$ & $\begin{array}{l}\text { They accomplish two most } \\
\text { reliably annotated corpora of } \\
\text { argument method in conversa- } \\
\text { tional argumentation generally } \\
\text { available. }\end{array}$ & $\begin{array}{l}\text { They presented annotation } \\
\text { requirements for each catego- } \\
\text { rization approach before } \\
\text { applying them to a corpus }\end{array}$ & $\begin{array}{l}\text { It is difficult to get an } \\
\text { optimal dataset. }\end{array}$ \\
\hline $\begin{array}{l}\text { Green } \\
\text { Nancy } 2016\end{array}$ & $\begin{array}{l}\text { They generated an argument } \\
\text { method in Prolog rules, and } \\
\text { matched the knowledge base } \\
\text { extracted from the body of each } \\
\text { rule from the text. }\end{array}$ & $\begin{array}{l}\text { They used the rule and } \\
\text { knowledge base, which are } \\
\text { easyily implemented in } \\
\text { prolog language. }\end{array}$ & $\begin{array}{l}\text { It has a limited domain } \\
\text { knowledge. }\end{array}$ \\
\hline $\begin{array}{l}\text { S. Gupta et } \\
\text { al. } 2017\end{array}$ & $\begin{array}{l}\text { They applied syntactic form and } \\
\text { dependency parsers to obtain } \\
\text { comparison form for biomedical } \\
\text { texts based on tree kernels for } \\
\text { justify their choice. }\end{array}$ & $\begin{array}{l}\text { Arguments are represented in } \\
\text { the }[0,1] \text { range, where }(1) \\
\text { indicates an argument that } \\
\text { can be easily interpreted. }\end{array}$ & $\begin{array}{l}\text { Every choice in the dataset } \\
\text { needs to be justified, } \\
\text { which requires large time } \\
\text { to be compared. }\end{array}$ \\
\hline $\begin{array}{l}\text { Wilk et al. } \\
2017\end{array}$ & $\begin{array}{l}\text { They proposed a clinical guide- } \\
\text { lines approachuUsing First order } \\
\text { logic (FOL) rules, then using a } \\
\text { graph for recommendations. }\end{array}$ & $\begin{array}{l}\text { It is a novel method that uses } \\
\text { preferences of patients. }\end{array}$ & $\begin{array}{l}\text { The limitation of the } \\
\text { represent FOL does not } \\
\text { allow for non-monotonic } \\
\text { changes, due to the use of } \\
\text { the graph. }\end{array}$ \\
\hline Green 2017 & $\begin{array}{l}\text { They proposed argument action } \\
\text { method and relations of inter- } \\
\text { argument for the annotation of } \\
\text { arguments in study articles . }\end{array}$ & $\begin{array}{l}\text { They investigated how argu- } \\
\text { mentation systems can be } \\
\text { implemented as logic pro- } \\
\text { grams. }\end{array}$ & $\begin{array}{l}\text { They use semantic predic- } \\
\text { tion tools }\end{array}$ \\
\hline Green $2018 b$ & $\begin{array}{l}\text { They implemented prolog lan- } \\
\text { guage as logic programs, used for } \\
\text { extracting individual arguments. }\end{array}$ & $\begin{array}{l}\text { It is relatively easy to be } \\
\text { implemented as a logic pro- } \\
\text { gram. }\end{array}$ & $\begin{array}{l}\text { It is difficult to extract } \\
\text { individual arguments }\end{array}$ \\
\hline $\begin{array}{l}\text { Kokciyan et } \\
\text { al } 2018\end{array}$ & $\begin{array}{l}\text { They apply argumentations to } \\
\text { reason with patient preferences, } \\
\text { and represent guidelines manual- } \\
\text { ly in first-order logic using the } \\
\text { argument method. }\end{array}$ & $\begin{array}{l}\text { The arguments are analyzed } \\
\text { to solve inconsistencies } \\
\text { concerning various treatment } \\
\text { options and patient prefer- } \\
\text { ences. }\end{array}$ & $\begin{array}{l}\text { The arguments are collect- } \\
\text { ed from different infor- } \\
\text { mation resources. }\end{array}$ \\
\hline $\begin{array}{l}\text { Tobias } \\
\text { Mayer }\end{array}$ & $\begin{array}{l}\text { They proposed extracting argu- } \\
\text { mentative information from }\end{array}$ & $\begin{array}{l}\text { New automatically tools to } \\
\text { extract claims and evidences }\end{array}$ & $\begin{array}{l}\text { Few diseases information } \\
\text { available in the dataset. }\end{array}$ \\
\hline
\end{tabular}


Paper-A Survey of Toulmin Argumentation Approach for Medical Applications

\begin{tabular}{|c|c|c|c|}
\hline $\begin{array}{l}\text { Reference } \\
\text { \&year }\end{array}$ & Approach & Advantages & Limitations \\
\hline et al. 2018 & $\begin{array}{l}\text { clinical data using an automated } \\
\text { methodology. }\end{array}$ & from clinical trials. & \\
\hline $\begin{array}{l}\text { Tobias } \\
\text { Mayer } \\
\text { et al. } 2019\end{array}$ & $\begin{array}{l}\text { They presented Argumentation } \\
\text { Clinical Trial Analysis (ACTA), } \\
\text { which is a tool designed to sup- } \\
\text { port clinicians in the analysis of } \\
\text { clinical trials. }\end{array}$ & $\begin{array}{l}\text { They developed tools to assist } \\
\text { doctors in clinical trial analy- } \\
\text { sis . }\end{array}$ & $\begin{array}{l}\text { They found the relations } \\
\text { between the argumentation } \\
\text { components. }\end{array}$ \\
\hline $\begin{array}{l}\text { Kristijonas } \\
\text { et al. } 2019\end{array}$ & $\begin{array}{l}\text { They suggested an advanced } \\
\text { structured argumentation formal- } \\
\text { ism for reasoning with conflict- } \\
\text { ing clinical guidelines. }\end{array}$ & $\begin{array}{l}\text { It provides great clinical } \\
\text { guidelines for health care } .\end{array}$ & $\begin{array}{l}\text { It is rather difficult to get } \\
\text { patients specific data. }\end{array}$ \\
\hline $\begin{array}{l}\text { Eli Moser \& } \\
\text { Robert E } \\
2020\end{array}$ & $\begin{array}{l}\text { They reported on and determined } \\
\text { a large scale argumentation form. } \\
\text { These models undergo a manual } \\
\text { examination. }\end{array}$ & $\begin{array}{l}\text { They used an argumentation } \\
\text { method to explain claims } \\
\text { based on experimental data }\end{array}$ & $\begin{array}{l}\text { Manual examination of the } \\
\text { articles is required. }\end{array}$ \\
\hline $\begin{array}{l}\text { Tobias } \\
\text { Mayer et al } \\
2020\end{array}$ & $\begin{array}{l}\text { They proposed an architecture for } \\
\text { classifying components of argu- } \\
\text { ments into claims and evidence, } \\
\text { and predicted the relation of } \\
\text { attack and support. }\end{array}$ & $\begin{array}{l}\text { They used the probability } \\
\text { theory for making decisions . }\end{array}$ & $\begin{array}{l}\text { It is difficult to obtain the } \\
\text { relations between argu- } \\
\text { mentative components. }\end{array}$ \\
\hline
\end{tabular}

After reviewing the most recent works in this area throughout this study, and identifying the most challenging aspects faces when adopting such approaches, the Toulmin's model for argumentation will be used to solve conflicting problems in the medical field. IT can also be used to support medical decisions in diagnosing the best suitable drugs to be given to patients, in an attempt to solve the conflicting issues related to drugs. This work summarized the previous works that have been conducted throughout the period (2014-2021).

\section{Conclusion}

Many recent ideas published in (2014-2021) are presented and discussed in this survey. The majority of studies produced in recent years have focused on the use of argumentation in conflict problems in different domains such as law, education and medicine. The argument remains tough as the amount of analyzed arguments grows and current techniques are further developed and brought together. The rapid improvement can be predicted when the number of analyzed arguments grows and current techniques are developed together. In this study, Toulmin's argumentation model is presented, along with some of the works that have deployed it. Besides Toulmin's model for solving conflict problems, many works are presented and mentioned, exploring several challenges faced it in this field in light of the mentioned corpora. Finally, it is stated how Toulmin's model has been utilized to deal with conflict problems and how it solves them. This study made use of Toulmin's model in the medical domain, with a focus on resolving drugs conflict problems through the applications of used remedies. 


\section{$5 \quad$ References}

[1] Amgoud, Leila. "A general argumentation framework for inference and decision making." 21st Conference on Uncertainty in Artificial Intelligence, UAI, pp.26-33. 2005.

[2] Toulmin, Stephen E. "The uses of argument." Cambridge university press, 2003.

[3] Sardianos, C., Katakis, I. M., Petasis, G., \& Karkaletsis, V."Argument extraction from news." Proceedings of the 2nd Workshop on Argumentation Mining. pp.56-66. 2015. http://dx.doi.org/10.3115/v1/W15-0508

[4] Williams, Matt, and Jon Williamson. "Combining argumentation and Bayesian nets for breast cancer prognosis." Journal of Logic, Language and Information, vol. 15, no.1, pp. 155-178, 2006. https://doi.org/10.1007/s10849-005-9010-x

[5] Toni, Francesca. "Argumentative agents." Proceedings of the international multiconference on computer science and information technology. IEEE, pp. $223-229,2010$. https://doi.or g/10.1109/IMCSIT.2010.5680035

[6] Dimopoulos, Yannis, Pavlos Moraitis, and Alexis Tsoukias. "Argumentation based modeling of decision aiding for autonomous agents." Proceedings. IEEE/WIC/ACM International Conference on Intelligent Agent Technology. IEEE, pp.99-105, 2004. https://doi.org/10. $\underline{1109 / \text { iat.2004.1342930 }}$

[7] Levy, Ran, et al. "Context dependent claim detection." Proceedings of COLING 2014, the 25th International Conference on Computational Linguistics: Technical Papers .pp.1489$1500,2014$.

[8] S. E. Toulmin, "The uses of argument". Cambridge university press, 2008.

[9] Wagemans, Jean. "Constructing a periodic table of arguments." Argumentation, objectivity, and bias: Proceedings of the 11th international conference of the Ontario Society for the Study of Argumentation (OSSA), pp.1-12. OSSA. 2016.

[10] Musi, Elena, Debanjan Ghosh, and Smaranda Muresan. "Towards feasible guidelines for the annotation of argument schemes." Proceedings of the third workshop on argument mining. 2016. pp. 82-93, 2016. http://dx.doi.org/10.18653/v1/W16-2810

[11] Čyras, Kristijonas, and Tiago Oliveira. "Resolving Conflicts in Clinical Guidelines using Argumentation." Proceedings of the 18th International Conference on Autonomous Agents and MultiAgent Systems. pp.1731-1739, 2019.

[12] Reisert, Paul, et al. "A computational approach for generating Toulmin model argumentation." Proceedings of the 2nd Workshop on Argumentation Mining. pp.45-55, 2015. http:// dx.doi.org/10.3115/v1/W15-0507

[13] Collins, Cynthia R. "Utilizing a logic model to identify clinical research problems: a lesson from philosophy of science." Nursing: Research and Reviews: vol.43, no.6,pp.43-49, 2016. https://doi.org/10.2147/nrr.s69798

[14] de e Oliveira Gabriel, V., Adamatti, D. F., Panisson, A. R., Bordini, R. H., \& Billa, C. Z. "Argumentation-based reasoning in BDI agents using Toulmin's model." 2018 7th Brazilian Conference on Intelligent Systems . IEEE, pp.378-383, 2018. https://doi.org/10.1109/br acis. 2018.00072

[15] Hong, Lee Yeng, and C. Abdul Talib. "Scientific argumentation in chemistry education: implication and suggestions." Asian Social Science, vol. 14, no. 11, pp. 14-29, 2018. https://doi.org/10.5539/ass.v14n11p16

[16] Admoko, S., Admoko, S., Suprapto, N., Deta, U. A., Achmadi, H. R., \& Hariyono, E. "Using Toulmin's Argument Pattern Approach to Identify Infodemics in the Covid-19 Pandemic Era." Journal of Physics, vol.1805. no.1, pp.11-20 ,2021. https://doi.org/10.1088/17 $\underline{42-6596 / 1805 / 1 / 012011}$ 
[17] N.B. Azhar, A. Al-zubidi, R. K. Hasoun, S. H. Hashim, and H. Salim, "Mobile A plication to Detect Covid-19 pandemic by using Classification Techniques.", International Journal of Interactive Mobile Technologies, vol.15, no.16, pp.34-51, 2021. https://doi.org/10.3991/ ijim.v15i16.24195

[18] Hunter, Anthony, and Matthew Williams. "Argumentation for aggregating clinical evidence." 2010 22nd IEEE International Conference on Tools with Artificial Intelligence. vol.1. IEEE, pp. 361-368,2010. https://doi.org/10.1109/ICTAI.2010.59

[19] Green, Nancy. "Identifying argumentation schemes in genetics research articles." Proceedings of the 2nd Workshop on Argumentation Mining, pp. 12-21, 2015. https://doi.org/10.3 $115 / \mathrm{v} 1 / \mathrm{w} 15-0502$

[20] Stab, Christian, and Iryna Gurevych. "Annotating argument components and relations in persuasive essays." Proceedings of COLING 2014, the 25th international conference on computational linguistics: Technical papers, pp.1501-1510, Dublin, 2014.

[21] Rivera, Francisco Javier Uribe, and Elizabeth Artmann."Physician-patient argumentation and communication, comparing Toulmin's model, pragma-dialectics, and American sociolinguistics." Cadernos de saude publica.vol.31 no.12, pp.2577-2587, 2015. https://doi.org/ $10.1590 / 0102-311 X 00150914$

[22] Jacky VISSER, John LAWRENCE, Jean WAGEMANS and Chris REED. "Revisiting computational models of argument schemes." 7th International Conference on Computational Models of Argument, COMMA 2018, pp.313-324, 2018. https://doi.org/10.3233/97 8-1-61499-906-5-313

[23] Walton, Douglas, Christopher Reed, and Fabrizio Macagno. "Argumentation schemes." Cambridge University Press, 2008.

[24] Nancy L. Green," Implementing argumentation schemes as logic programs”. In Proceedings of the 16th Workshop on Computational Models of Natural Argument, volume 1876 of CEUR Workshop Proceedings, pp.1-7, 2016.

[25] Wilk, S., Michalowski, M., Michalowski, W., Rosu, D., Carrier, M., \& Kezadri-Hamiaz, M. "Comprehensive mitigation framework for concurrent application of multiple clinical practice guidelines.” Journal of Biomedical Informatics, vol.66, no.5, pp.52-71, 2017. https://doi.org/10.1016/j.jbi.2016.12.002

[26] Green, Nancy. "Manual identification of arguments with implicit conclusions using semantic rules for argument mining." Proceedings of the 4th Workshop on Argument Mining.pp. 73-78, 2017. https://doi.org/10.18653/v1/w17-5109

[27] S. Gupta, A. S. M. A. Mahmoud, K. Ross, C. H. Wu, and K. Vijay-Shanker. "Identifying comparative structures in biomedical text.” In BioNLP , pp.206-215, 2017. https://doi.org/ $\underline{10.18653 / \mathrm{v} 1 / \mathrm{w} 17-2326}$

[28] Green, Nancy L. "Towards scientific discourse using argumentation schemes." Argument \& Computation, vol.9, no. 2,pp.121-135, 2018b. https://doi.org/10.3233/aac-180038

[29] Tobias Mayer, Elena Cabrio, Marco Lippi, Paolo Torroni, and Serena Villata,"Argument mining on clinical trials". In Proceedings of the 7th International Conference on Computational Models of Argument (COMMA), pp. 137-148, 2018.

[30] Kokciyan, N., Sassoon, I., Young, A. P., Chapman, M., Porat, T., Ashworth, M. \& Sklar, E. "Towards an Argumentation System for Supporting Patients in Self-Managing their Chronic Conditions". Workshops at the Thirty-Second AAAI Conference on Artificial Intelligence. 2018.

[31] Thanh.TTP1, Giao N. Pham1, Jin-Hyeok Park1, Kwang-Seok Moon2, Suk-Hwan Lee3, and Ki-Ryong Kwon1. "Acute leukemia classification using convolution neural network in clinical decision support system." CS \& IT Conference Proceedings. vol. 7. No. 13, 2017. 
[32] Mayer, Tobias, Elena Cabrio, and Serena Villata. "ACTA: A Tool for Argumentative Clinical Trial Analysis." IJCAI 2019-Twenty-Eighth International Joint Conference on Artificial Intelligence. pp.6551-6553, 2019. https://doi.org/10.24963/ijcai.2019/953

[33] Eli Moser and Robert E. Mercer, "Use of Claim Graphing and Argumentation Schemes in Biomedical Literature: A Manual Approach to Analysis", Proceedings of the 7th Workshop on Argument Mining, pp.88-99, Spain, December, 2020.

[34] ARROYO, Ivon, and Beverly Park WOOLF. "Inferring learning and attitudes from a Bayesian Network of log file data." Artificial Intelligence in Education: Supporting Learning Through Intelligent and Socially Informed Technology, vol.125, no. 33, pp.33-40, 2005.

[35] Tobias Mayer, Elena Cabrio, and Serena Villata," Transformer-based Argument for Healthcare Applications". 24th European Conference on Artificial Intelligence(ECAI), IOS Press. pp. 2108-2115. Spain, 2020.

\section{$6 \quad$ Authors}

Hamzah Noori Fejer is a PhD student in Computer Science \& Information Technology, Babylon university, Babylon, Iraq.

Ali Hadi Hassan is an associate professor in Computer Science \& Information Technology, Babylon university, Babylon, Iraq.

Ahmead Tariq is professor in Computer Science \& Information Technology, Technlogyah university, Baghdad, Iraq.

Article submitted 2021-11-02. Resubmitted 2021-12-17. Final acceptance 2021-12-18. Final version published as submitted by the authors. 